\title{
EL LÉXICO OLIGÁRQUICO EN EL LIBRO VIII DE TUCÍDIDES
}

\author{
Paulo Donoso Johnson \\ Instituto de Historia, \\ Pontificia Universidad Católica de Valparaíso. Chile
}

Resumen: Este artículo analiza algunos conceptos presentes en el libro VIII

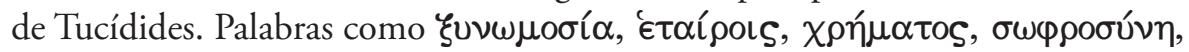
фóßos, adquieren un sentido distinto influido por el contenido psicológico que el historiador imprime a su obra.

Estos conceptos permiten entender los sucesos del 411 a.C. y las perspectivas del historiador durante los últimos años de la Guerra del Peloponeso.

Palabras claves: Oligarquía - Tucídides - etimología - teoría política

\section{THE OLIGARCHIC LEXICON IN THE VIII BOOK OF THUCYDIDES}

Abstract: This article intend to analyse some concepts inside in the Thucydides

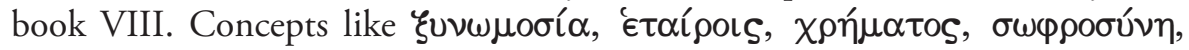
óßos, acquire a different sense influenced by the psychological content that the historian prints in his work.

These words allow understand the events of the 411 B.C. and the Thucydides perspectives during the last years of the Peloponnesian WAR.

Keywords: Oligarchy - Thucydides - etymology - political theory

Recibido: 4.03.2014 - Aceptado: 10.04.2014

Correspondencia: Paulo Donoso Johnson paulo.donoso@ucv.cl

Profesor Instituto de Historia, Pontificia Universidad Católica de Valparaíso Pontificia Universidad Católica de Valparaíso. Paseo Valle 396, Viña del Mar, Chile. Fono: (39) 3427566708 
T a decadencia del sistema político ateniense, otrora el modelo más destacado en las polis griegas y con una inusitada participación de amplias mayorías que decidían los aspectos cotidianos y a la vez relevantes de sus asuntos políticos y económicos, verá disminuido su capacidad y la posibilidad de evitar liderazgos múltiples. El ostracismo para finales del siglo $\mathrm{V}$ a.C. se había convertido en una herramienta de corrupción y manejo de votos para ciertos grupos políticos con intereses particulares mayor cantidad de ciudadanos posibles. La existencia de diferencias políticas irreconciliables entre los líderes demarcará ciertos límites en torno a qué tipo de democracia era la más viable y bajo qué orientación ideológica era posible culminar la guerra con un triunfo para Atenas. Este debate quedará instalado hasta el momento de la reorganización de los grupos oligárquicos ${ }^{1}$ quienes en su mayoría tenían un pasado democrático y su reacción obedecerá en gran medida a la presencia de líderes dañinos para la polis, como Alcibíades, que representa la praxis política más que al proyecto político en sí.

Luego de la muerte de Cleón, la traición de Alcibíades y la derrota en Sicilia, la posición bélica ateniense fue inferior a la de Esparta y por ende el régimen tenía los días contados. La consolidación de la alianza persa-espartana no hará sino que romper el enorme muro de Temístocles (el imperio naval) mermado luego del desastre en Siracusa. Esta realidad resucitará los antiguos afanes de restaurar la oligarquía y conceder el mando a los notables de la polis. Es por tanto

\footnotetext{
${ }^{1}$ En virtud de la precisión he decidido dejar fuera el análisis sobre los Cuatrocientos, su constitución oligárquica y la identidad de sus integrantes. Sobre este tema Vs. Tucídides Libro VIII, 73 98; Aristóteles, Constitución de los Atenienses, 29 - 32; Jenofonte, Helenicas Libro II; Donini, G. (1969) "La posizione di Tucidide verso il governo dei Cinquemila" Paravia, Torino; Grossi, G. (1984) "Frinico. Tra propaganda democratica e giudizio tucidideo" L'Erma di Bretschneider, Roma; Sartori, F. (1951), "La crisi del 411 a.C. nell'Athenaion Politeia di Aristotele" CEDAM, Padova; Avery, H.C. (1984), "Prosographical studies in the oligarchy of the Four Hundred" Ann Arbor, Michigan.
} 
una suerte de desesperación y pérdida del rumbo del régimen democrático lo que permite la llegada de los oligarcas al poder y no sólo la consecuencia directa de una campaña conspirativa ${ }^{2}$.

Sin entrar a discutir sobre las dificultades y dudas que aún se mantienen sobre la composición del libro VIII de Tucídides ${ }^{3}$, podemos introducirnos a través del léxico que el historiador utilizó para referirse a los acontecimientos previos y posteriores al año 411 a.C. cuando deviene la conspiración oligárquica contra la democracia en Atenas.

Mi aproximación etimológica busca entender desde la fuente misma la forma desde la cual el historiador describe los acontecimientos sin dejar de lado el componente analítico que sugiere cada concepto utilizado. Precisamente serán los aticismos empleados los que dan vida y recrean magistralmente esta etapa de incertidumbre y confusión, en una obra que deja bastantes vacíos debido a su abrupto final.

Como primera aclaración es menester decir que un léxico de tipo "oligárquico" obedece a una construcción argumentativa dada por el mismo historiador y no a una imitación de otras obras. Partimos del supuesto de la originalidad de la obra y que las demás fuentes escritas de este período (Pseudo-Jenofonte, Heródoto, Helánico, Píndaro, Aristófanes, Esquilo, Sófocles y Eurípides) sólo aportaron un contexto lingüístico propicio. No obstante los conceptos detallados a continuación son utilizados reiteradamente por nuestro Tucídides el ateniense. El lenguaje aportado por la tragedia y la historia aportan una gama de significados para referirse a la oligarquía, incorporados en adjetivos que se refieren a los pocos como

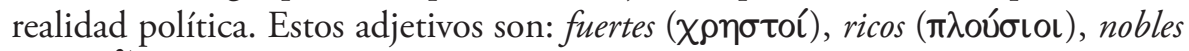

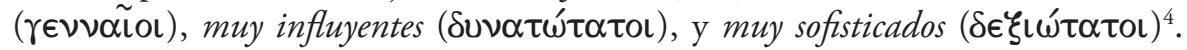
Otro significado que ha sido sugerido siguiendo el léxico de Tucídides es el de

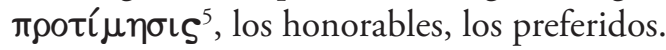

2 "El movimiento revolucionario constituía una respuesta a la situación bélica" Ferguson W.S. (1953)

"The Oligarchy in Athens" The Cambridge Ancient History Volume V, Cambridge University Press, p. 365.

${ }^{3}$ Vs. Canfora, L. "Tucidide Continuato", Ed. Antenore, Padova, 1970.

${ }^{4}$ Ostwald, M. (2000), "Oligarchia. The Development of a Constitutional form a ancient Greece" HISTORIA, Heft 144, pp. 23 - 24.

${ }^{5}$ Vs. Graham, A.J. - Forsythe, G. (1984), "A New Slogan for Oligarchy in Thucydides III.82.8" en Harvard Studies in Classical Philology, Harvard University Press. 
Para una mayor comprensión de los conceptos he decidido incorporarlos sin las declinaciones con las que aparecen en el texto, sin embargo, con el fin de respetar el aspecto natural de cada palabra serán revelados bajo su forma ática original.

En segundo lugar, el ordenamiento de los conceptos estará dado según una cierta concordancia de significado incorporando una breve didaskaleía *del contexto en el cual son utilizados.

Conceptos de acción politica explicita:

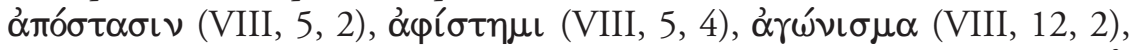

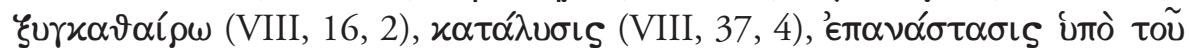

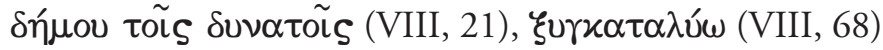

Conceptos de acción politica implícita:

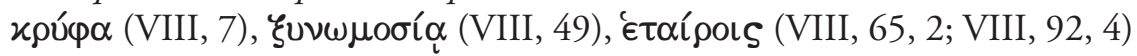

Conceptos de teoría y grupos politicos:

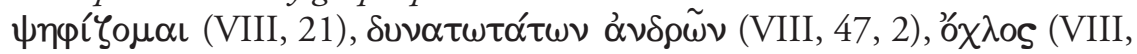

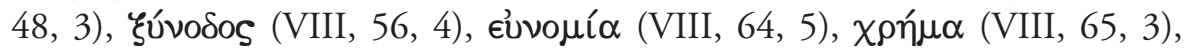

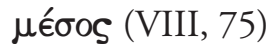

\section{Conceptos morales y cualitativos:}

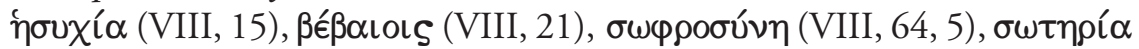

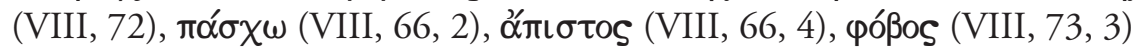

\section{Acción política explícita}

Hablar de acción política explícita quiere decir aquello que evidencia una actitud concreta de parte de de los grupos reducidos que deseaban derribar

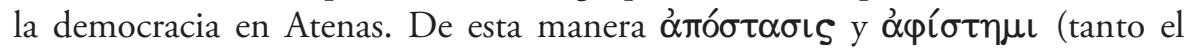
sustantivo como el verbo) denotan la sublevación y la rebelión, entendidas por Tucídides como una acción tangible que está latente entre muchos de los líderes que ven el constante desvarío de la democracia principalmente desde la asunción

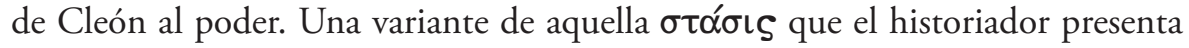
y define en el libro III con motivo de la guerra civil de Córcira ${ }^{6}$. Son quizás los

* La traducción española desde donde he tomado los párrafos citados corresponde a la de Francisco Rodríguez Adrados (2002).

${ }^{6}$ Vs. López Eire, A.(1990) "La revolución en el pensamiento politico de Tucídides (I)" Gerión No 8, Universidad Complutense de Madrid. 
conceptos más evidentes y que se repiten a lo largo de todo el libro VIII con el fin de profundizar el estado de inseguridad e debilidad del Estado ateniense luego del desastre en Sicilia el 415 a.C. En este mismo sentido, dice Luciano Canfora que, el lenguaje de la conspiración política está constituido de palabras elementales

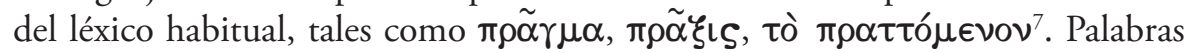
que denotan la insoslayable realidad práctica que contiene el concepto de tomar el poder por la fuerza teniendo o no el apoyo popular.

De todos los conceptos, uno de los más utilizados por Tucídides en toda su obra y que demuestra el carácter literario que contiene su creación es el de $\alpha \gamma(\omega ́ v \iota \sigma \mu \alpha$. Esta palabra refuerza la raíz $\alpha \gamma u ́ v$ con el fin de destacar el sentido del enfrentamiento, la contienda y la lucha entre facciones que terminaron por quebrar la debilitada unidad griega durante la era clásica. La guerra en sí misma contiene este sentido agonal, sin embargo la lucha entre grupos políticos al interior de una ciudad conlleva a que la contienda sea aún más corrosiva. De esta manera la guerra contra Esparta se convirtió en una guerra contra todo aquello que representaba el mundo espartano, es decir, la aristocracia dominante y sus redes de poder que inmovilizaba cualquier tipo de cambio a la legislación tradicional denominada Retra.

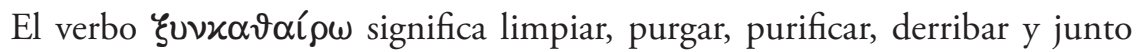

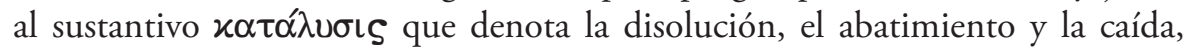
representan aquello que deliberadamente fue llevado a cabo el año 411 a.C. por el grupo de oligarcas liderado por Pisandro. El abatimiento de la democracia, según narra Tucídides fue derribada inicialmente en la isla de Samos, bastión del poderío naval ateniense y posteriormente en Atenas. La oligarquía no necesita de las instituciones democráticas para gobernar sino más bien de un selecto grupo de líderes ${ }^{8}$ que cumplan las funciones que anteriormente eran de la competencia del demos y la Asamblea.

A pesar de lo anterior, esta lucha no es unidireccional y la mayoría accede habitualmente a recuperar lo que por derecho les pertenece. Ésto se ve reflejado en

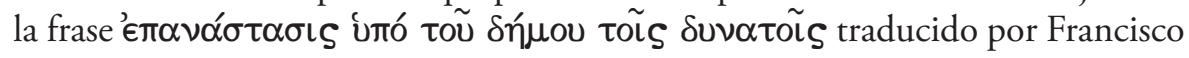

${ }^{7}$ Canfora, L. (1980) “Oratoria Politica e Giudiziaria in Atene" en Atti del Convegno sulla Lessicografia Politica e Giuridica nel campo delle scienze dell'Antichità (Torino, 28-29 aprile 1978), Torino, p. 85.

8 "They adopted the hypothesis that certain classes which might be qualified by birth and wealth, or birth and training, or by wealth alone, were fit to rule over others, who were not fit to rule" $V s$. Whibley, L. (1896) "Greek Oligarchies. Their character and organisation" Methuen \& Co, Cambridge, p. 36. 
Rodríguez Adrados como la sublevación del pueblo contra los nobles ${ }^{9}$, que a través del libro VIII de Tucídides y luego en el Libro I y II de las Helénicas de Jenofonte se puede comprobar como la contrarreacción de los grupos democráticos más radicalizados que terminaron por condenar a muerte al líder del movimiento oligárquico, Terámenes ${ }^{10}$.

Finalmente en este grupo de conceptos de acción explícita se encuentra uno que ya hemos visto anteriormente pero que Tucídides lo individua en el líder

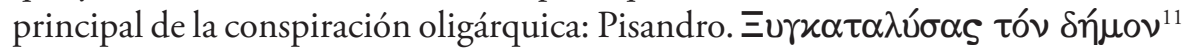
es traducido en el contexto tanto por Rodríguez Adrados como por Ferrari ${ }^{12}$ y De Romilly ${ }^{13}$ como el ardiente afán del mencionado oligarca por abatir la democracia, quizás el verbo que predomina sobremanera en los acontecimientos del 411 a.C. que convulsionaron la trizada convivencia social ateniense.

\section{Acción política implícita}

Siguiendo el orden analítico de este ensayo conceptual es posible decir que la acción política implícita significa todo aquello que Tucídides no dice o explica abiertamente y que sin embargo da a entender a través de las consecuencias de las acciones realizadas por grupos partidarios o bien personajes individuales. Esto quiere decir que, desde el lenguaje escrito, el historiador incorpora nociones teóricas que sugieren la necesidad de leer "entre líneas" y comprender según el contexto aquello que desea revelar. Es por tanto que en este apartado se verá el desacuerdo entre los tres traductores ya mencionados en torno a uno de los conceptos.

En primer lugar, $\varkappa \rho u ́ \varphi \alpha$ usado como adverbio tiene el sentido del secreto, hacer algo en secreto. Su uso con genitivo nos revela el hecho de hacer algo a escondidas, a espaldas de alguien. Ambos significados crean el primer aspecto revelador del golpe oligárquico, fue planeado en el más absoluto hermetismo, de manera que al manifestarse el grupo liderado por Pisandro y sus seguidores, Tucídides llega a decir:

\footnotetext{
9 Tucídides, (2002) "Historia de la Guerra del Peloponeso", Centro de Estudios Políticos y Constitucionales, Madrid, p. 428.

${ }^{10}$ Xénophon (1960) “Helléniques”Les Belles Lettres, Paris, Livre II, 3.

${ }^{11}$ Tucídides VIII, 68.

${ }^{12}$ Tucidide (2011) "La Guerra del Peloponneso"BUR Rizzoli, Classici Greci e Latino, Milano, p. 1379.

13 Thucydide (2003) "La Guerre du Péloponnèse” Les Belles Lettres, Paris, p. 54.
} 
"Efectivamente, todos los del partido popular se miraban unos a otros con recelo, como si cada uno de ellos tomara parte en lo que sucedia. La causa era que habia hombres que nadie hubiera creido nunca que se pusieran al lado de la oligarquia"14.

Este revelador fragmento es pilar fundamental para la tesis que sostiene Luciano Canfora ${ }^{15}$ sobre la participación directa del historiador ateniense en estos hechos debido al conocimiento de movimientos políticos muy precisos. En este sentido, Pierre Huart en su noción psicológica del léxico tucidídeo aborda un concepto que mucho tiene que ver con el mencionado anteriormente: $\alpha \iota \sigma \vartheta \alpha^{\prime} \boldsymbol{\epsilon} \sigma \vartheta \alpha \iota$ en tanto presentimiento, cuando los demócratas de Samos presienten un complot de oligarcas (VIII, 73, 4) ${ }^{16}$. Es por tanto el clima de miedo ${ }^{17}$ acerca de los hechos que estaban por presentarse el que genera un ambiente particular que Tucídides comienza a sugerir desde el primer momento, una vez anunciado el desastre de Sicilia en Atenas.

En segundo lugar, tomando en cuenta la amplia riqueza de significado que nos ofrece la lengua griega, Tucídides da a conocer el concepto más interesante que

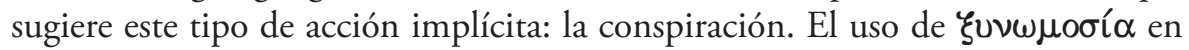
su morfología ática que utiliza la $\xi$ en vez de $\sigma$ inicial, conlleva todo aquello que involucra la conspiración, es decir, conjura o juramento. Sin embargo, también significa facción, partido y confederación. Es por tanto un concepto que puede llevar al error si no se traduce analizando el contexto. Cabe destacar que es una de las palabras más utilizadas en el libro VIII dando a entender de esta manera el clima de constantes traiciones que se llevaban a cabo entre los distintos grupos políticos, en el marco del secreto anteriormente detallado.

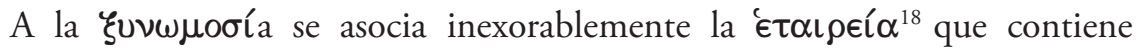
amplios significados, desde la denominación de las concubinas de la Grecia clásica hasta el partido político como realidad corporativa. Es un concepto que se utiliza frecuentemente pero ha sido traducido diversamente según el contexto

${ }^{14}$ Tucídides VIII, 66, 5.

${ }^{15}$ Canfora, L. (2001), “El misterio Tucídides” Aldebarán Ediciones, Madrid.

${ }^{16}$ Huart, P. (1968) "Le vocabulaire de l'analyse psychologique dans l'oeuvre de Thucydide” Librairie C. Klincksieck, Paris.

17 "l'historien grec nous parle bien des nouvelles recuillies auprès des prisionners échappés (VIII, 1,1), mais, sil indique à Athènes une atmosphère extraordinaire de terreur et d'effroi" Ídem, p. 62.

${ }_{18}$ Vs. Sartori, F. (1957) "Le eterie nella vita politica ateniese del VI e V secolo a.C." L'Erma di Bretschneider, Roma, cap. I. 
del texto griego original. Para Rodríguez Adrados tiene una clara connotación conspirativa al traducirlo como sociedades secretas, aquellas que colaboraron con Pisandro a derribar las democracias de las ciudades costeras de Grecia ${ }^{19}$. El filólogo italiano Franco Ferrari prefiere referir el término como conjurados en el mismo párrafo anteriormente citado y luego como sociedad politica en el episodio de la construcción del muro en el Pireo por parte de los Cuatrocientos ${ }^{20}$. Finalmente, en este último evento el concepto será traducido por Mme. De Romilly como partido ${ }^{21}$. La discusión reciente sobre la ambigüedad de ambos conceptos ha llegado a dilucidar una sutil diferencia de significado. El concepto

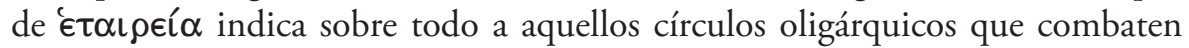
su lucha antidemocrática en los límites de una oposición reconocida y tolerada por la ley ${ }^{22}$, en cambio la $\xi u \nu \omega \mu o \sigma i ́ \alpha$ refiere a una conspiración organizada y abiertamente inconstitucional ${ }^{23}$. Una diferencia que en al momento de ser llevada a cabo cambia completamente su sentido.

\section{Teoría y grupos políticos}

Siguiendo adelante con este análisis nos encontramos con aquellos conceptos que refieren a la teoría política en cuanto a sistema de partidos o nociones de clases sociales asociadas a la vida pública.

El primero de ellos es un verbo en forma media pasiva, $\psi \eta \varphi$ '́ guarda relación con el acto de votar, el sufragio ${ }^{24}$ que permite la elección de los magistrados y cargos representativos. Es la decisión soberana e informada del $\delta \tilde{\eta} \mu \circ$ s e instrumento inquebrantable de la democracia griega. Sin embargo

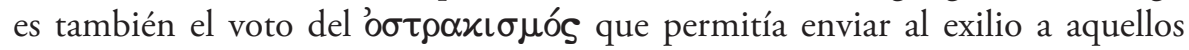
ciudadanos que, o bien eran considerados un mal para la sociedad, o su presencia

${ }^{19}$ Tucídides, VIII, 65, p. 451.

${ }^{20}$ Tucidide, VIII, 92, 4, p. 1417.

${ }^{21}$ Thucydide, Livre VIII, 92, 4, p. 78.

22 Sartori, F. Op. Cit. P. 71.

${ }^{23}$ Cf. Hornblower, S. (2008) "A Commentary on Thucydides" Vol III, Oxford University Press, pp. 916 - 920 donde el autor repasa la ambigüedad conceptual a partir de Thesaurus Linguae Graecae donde la significación tiene un claro contenido moral negativo; Gomme, A.W., Andrewes, A., Dover, K.J. (1981), "A Historical Commentary on Thucydides" Oxford Clarendon Press, dice que esta $\xi u \nu \omega \mu o \sigma i ́ \alpha$ parece no existir para el desarrollo de un principio político sino para el beneficio de sus miembros en las elecciones y demandas en el marco del régimen existente, $\mathrm{p}$ 129. Una visión que acerca la conjuración a un acto político dentro de los parámetros de la ley.

${ }^{24}$ suffragium ferre y sententiis decernere, da la idea del sufragio inmutable y resolutivo. Bétant, E.A (19612), “Lexicon Thucydideum” Hildesheim: G. Olms, p. 517. 
en la vida política disturbaba el correcto ordenamiento social ${ }^{25}$. El ostracismo también valía para aquellos ciudadanos que ameritaban algún tipo de punición por poner en riesgo la seguridad de la polis como es el caso del mismo historiador luego del fracaso de la misión contra el general espartano Brásidas y la captura de Anfípolis ${ }^{26}$. Precisamente el sufragio democrático será el primer derecho en ser abolido por la oligarquía reduciendo así la capacidad de decisión de la Asamblea. De esta manera, los Cuatrocientos representantes que toman el poder el 411 harán votar bajo presión al $\delta \tilde{\eta} \mu o \varsigma$ reunido en un barrio cercano a Atenas, Colonos, en un reducido espacio elegido deliberadamente para intimidar y obligar a aprobar al pueblo una constitución de tipo oligárquica que permitiese a los conjurados tomar el poder. Tampoco es casualidad que la Asamblea y su espacio democrático del $\Pi \nu \iota \xi$, mirando hacia el Pireo fuera restituido por un teatro en Colono obligando al pueblo a decidir de espaldas al mar, símbolo del imperio talasocrático que había logrado la democracia ateniense. Es pues la $€ \lambda \in \cup \vartheta € \rho i ́ \alpha$ que se ve reflejada en el sufragio la cual será restituida por un gobierno basado en la posesión económica ${ }^{27}$.

$\Delta v \nu \alpha \tau \omega \tau \alpha \tilde{\tau} \omega \nu \alpha^{\alpha} \nu \delta \rho \tilde{\omega} \nu$ nos conduce directamente al sentido homérico de la fuerza y el vigor masculino que por antonomasia eran llamados a dirigir los ejércitos y ocupar los cargos públicos. Los más influyentes podría ser una de las traducciones correctas evidenciando así la raíz etimológica que nos lleva al verbo $\delta u ́ v \alpha \mu \alpha$ que recae en $\delta u ́ v \alpha \mu \iota \varsigma$, la fuerza, el poder físico y posteriormente

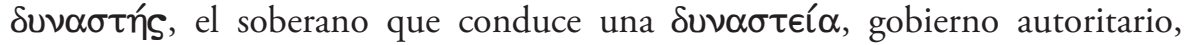
definido algunas veces como tiranía ${ }^{28}$ y en otros casos como oligarquía ${ }^{29}$. Un recorrido lingüístico que permite visualizar la esencia de este grupo político que desde su nomenclatura ostenta la fuerza física y la autoridad.

${ }^{25}$ El caso particular de Tucídides de Melesias, líder de la aristocracia que es enviado al exilio por voto popular debido a sus constantes acusaciones en contra de Pericles; por otra parte Hipérbolo es condenado al ostracismo debido a su deshonestidad y por avergonzar a la patria. Tucídides Libro VIII, 73, 3

26 Tucídides IV, $104-108$.

${ }^{27}$ Aquí reside la gran diferencia de la oligarquía con la aristocracia. Esta última según la tradición

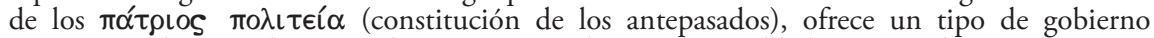
que asegura la paz y la concordia interna, sin destruir la igualdad. Vs. Cecchin, S.A. (1969),

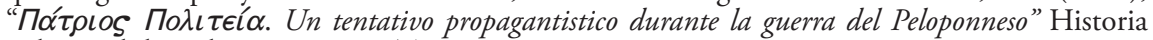
Politica Philosophica 1, Paravia, Torino.

${ }^{28}$ Vs. Plácido, D. (1989) “Tucídides, sobre la tiranía” en Gerión, Anejos II, Estudios sobre la antigüedad en homenaje al profesor Santiago Montero Díaz, Universidad Complutense de Madrid.

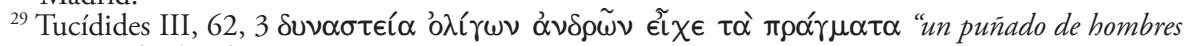
posee todo el poder". 
El concepto de ö $\chi \lambda$ os es posible traducirlo como masa, sin embargo en el contexto, Tucídides lo usa para referirse a la masa de los soldados que en Samos colaboraron con los oligarcas para derribar la democracia y solicitar los favores que ofrecía el rey Persa. No es posible encontrar una referencia al pueblo como masa según la definición de Bétant que propone turba y molestus ese ${ }^{30}$. La definición de los grupos políticos y formas de gobierno la encontraremos posteriormente en Platón y Aristóteles respectivamente, no obstante un texto contemporáneo a Tucídides, Athenaion Politeía, atribuido a Pseudo-Jenofonte, utiliza habitualmente el concepto de ó $\chi \lambda$ os con el fin de desprestigiar la democracia. Según se ha sostenido, este texto pudo haber sido un escrito de juventud del propio Tucídides ${ }^{31}$. De todas formas, es un concepto poco recurrente en la ecuanimidad histórica que trata de aplicar el historiador en su obra y es posible encontrarlo de manera reiterativa en la comedia griega. En cambio un sinónimo adecuado y utilizado con frecuencia en el texto tucidídeo es el de $\pi \lambda \tilde{\eta} \vartheta$ os que conlleva un sentido de ciudadanía organizada ${ }^{32}$ o mejor dicho la población ${ }^{33}$.

Al hablar de Gúvodos el historiador convierte la reunión o el encuentro entre grupos políticos o representantes en un acto ceremonial. Este concepto aparece mencionado en el contexto del tercer tratado de los peloponesios con el Rey persa que permitía el ingreso del antiguo rival oriental en la guerra interna contra Atenas. 三úvodos entendido como conventus, congressus ${ }^{34}$ nos revela una idea

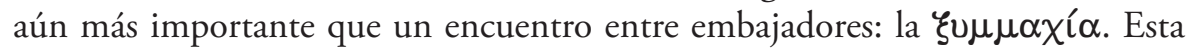
última definible como alianza y tratado nos conduce al léxico de la diplomacia y las relaciones internacionales que los atenienses aprendieron a utilizar tempranamente a medida que su imperio crecía. En este sentido es evidente el cambio del estilo narrativo de manera que el lenguaje histórico-narrativo se convierte en una descripción jurídica formal ausente de cualquier adjetivo que pudiera restar el valor protocolar de estos encuentros.

La €ủvouí $\alpha$ como tal representa el mayor objetivo del mundo griego clásico con respecto a la vida cívica. Si la primera noción que nos da Tucídides en el

\footnotetext{
${ }^{30}$ Bétant, E.A. Op. Cit., p. 265.

31 "Tucidide oligarca e addiritura autore, in gioventù, della pseudosenofontea Costituzione di Atene (Wilhelm Nestle)" Canfora, L (1992) "Hobbes e Tucidide"QS, No35, p. 69.

${ }^{32}$ Cf. Silvestrini, M. (1976) "Diplomazia e complotti oligarchici a Chio e Rodi (Tucidide, VIII, 5 44)" QS, No 3, p. 285.

${ }_{33}$ Pope, M (1988), "Thucydides and Democracy", HISTORIA, Band XXXVII, p. 284.

${ }^{34}$ Bétant, E.A., Op. Cit. p. 213.
} 
discurso fúnebre está relacionada con la eủdolı $\mu$ oví $\alpha^{35}$, es decir la felicidad, la $\epsilon u \nu o \mu i ́ \alpha$ como buen gobierno es el principal vector para este objetivo principal. Si bien es cierto el buen gobierno es para todos los ciudadanos aquello que les permite desenvolverse libremente en todos los ámbitos de la vida pública y privada, serán los oligarcas, quienes, siguiendo la tradición aristocrática de la

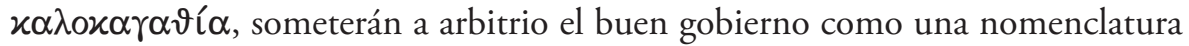
propia del orden que ofrece un grupo reducido de dirigentes autoelegidos, acentuando la idea polarizante de la $\delta \iota \sigma \nu o \mu i ́ \alpha$ como sinónimo de gobierno democrático. El contexto utilizado por Tucídides para presentarnos la €ủvouí $\alpha$ es precisamente el engaño de los oligarcas al implantar un sistema que fue rechazado por los atenienses ${ }^{36}$ en donde se ve con notoriedad esta noción de protección al orden constitucional ${ }^{37}$.

Siguiendo adelante en este análisis aparece uno de los conceptos más importantes e indispensables para diferenciar a la oligarquía de los otros grupos políticos: la riqueza y superioridad económica. El vocablo $\chi \rho \eta ́ n \alpha$ señala el dinero, los asuntos de administración económica y los bienes materiales. Sabemos que el estudio más profundo y dedicado sobre este concepto lo encontramos en Aristóteles, sin embargo, tempranamente Tucídides da cuenta de la interferencia de la riqueza económica y los asuntos políticos en el discurso de Atenágoras ${ }^{38}$ describiendo de esta forma aquello que validaba el derecho a gobernar a un grupo reducido de líderes. Acerca de la relación riqueza - oligarquía, un historiador británico del siglo XIX dice que:

${ }^{35}$ Vs. Tucídides II, 44, 1.

${ }^{36}$ Tucídides VIII, 64, 5 "Así pues, en lo que a Tasos respecta las cosas les salieron al revés que a los atenienses que intentaban implantar la oligarquía, y a mi ver lo mismo ocurrió en el caso de otros muchos de entre los vasallos: pues las ciudades, al adquirir cordura y libertad de acción, buscaron la independencia completa, no interesándoles el falaz buen gobierno ofrecido por los atenienses"; $V s$. también el "buen orden" asociado tradicionalmente con Licurgo, la palabra es aqui transferida al estado de asuntos que los oligarcas atenienses pretendian introducir. Hornblower, S. Op. Cit., p. 943.

${ }^{37}$ La versión italiana de Ferrari traduce eủvo $\mu$ í $\alpha$ como "buona costituzione” Tucidide, VIII, 64, 5, p. 1375.

${ }^{38}$ Tucídides VI, 39 "Alguien dirá que la democracia no es ni razonable ni justa y que los dueños del dinero son los más aptos para gobernar mejor. Pero yo afirmo, en primer lugar, que el pueblo es la totalidad de la ciudad y los oligarcas sólo una parte; y en segundo, que los ricos son los mejores guardianes del dinero, pero tienen mejor juicio en las decisiones los hombres inteligentes y juzga mejor la multitud una vez informada del asunto de que se trate, y que estas tres clases de ciudadanos tienen en una democracia igualdad de derechos, tanto cada una aisladamente, como todas juntas. En cambio los oligarcas hacen participar en los peligros a la multitud, pero en cuanto a las ventajas, no sólo llevan la mejor parte, sino que se apropian de todas: esto es lo que desean los poderosos y los jóvenes de entre vosotros, siendo imposible que lo consigan en una ciudad populosa como ésta". 
"De las oligarquias basadas en la riqueza solo unas pocas se habian desarrollado sin violencia a partir de los antiguos gobiernos aristocráticos, pera la mayoría de ellas eran fruto de revoluciones, creaciones diseñadas para satisfacer las nuevas condiciones sociales $o$ instituidas sobre la base de una colonia comercial. La riqueza era el principio de la constitución, y el objetivo de los ciudadanos" 39.

De tal manera y siguiendo a Whibley, "el oligarca asume una superioridad moral y mental y posee elementos de la cultura que sólo los ricos pueden alcanzar" " ${ }^{0}$. Una diferencia radical con las antiguas aristocracias que precisamente fundamentaban en el $\alpha \rho € \tau$ sus regímenes.

\section{Conceptos morales y cualitativos}

En este último grupo de conceptos de teoría política es menester incluir uno que particularmente atañe al mismo historiador en relación a su propia militancia política. La idea de $\mu$ é́os, la cual hace referencia al medio, la mitad, el centro. Este medio en Tucídides tiene un carácter político y concierne a la moderación entendida como el punto medio entre la radicalizada democracia y la desbordada oligarquía que el historiador rechazaba. Aún cuando la historiografía ha tratado de ubicar al historiador ateniense en las filas de la oligarquía radical ${ }^{41}$ su propio testimonio, deducido a través de la descripción de Nicias como un líder excepcional ${ }^{42}$ y a quién personalmente admiraba, permite desmentir esta versión. En este caso los grupos moderados tendrán un importante rol pacificador en las luchas internas entre demócratas y oligarcas. Relata Tucídides en el episodio de la conjura oligárquica en Samos y la reacción demócrata un ejemplo sobre el papel del partido moderado:

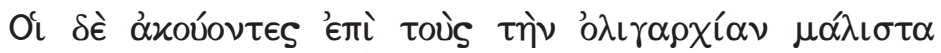

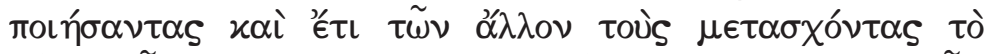

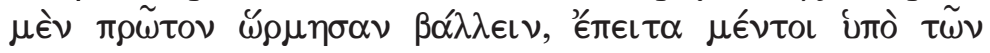

\footnotetext{
${ }^{39}$ Whibley, L, Op. Cit. p. 30.

${ }^{40}$ Ídem, p. 39.

${ }^{41}$ Vs. Canfora, L. El misterio Tucídides, Op. Cit.; Even Grote "enemigo de la democracia”; Karl Popper "ciertamente un miembro del partido oligárquico", Malcolm McGregor "terminó su vida como el habia querido, un confirmado oligarca el cual nunca renunció al credo de sus padres"; Connor, "Tucidides rechazó vivir con cliché", Ste Croix "la impresión permanece como un duro antidemócrata" Cf. Pope, M, Op. Cit., p. 276.

${ }^{42}$ Tucídides VII, 86, 5 "Por estas o parecidas razones murió Nicias, el menos digno de los griegos de mi tiempo de llegar a tan gran infortunio; pues gobernó siempre su conducta de acuerdo con la virtud".
} 


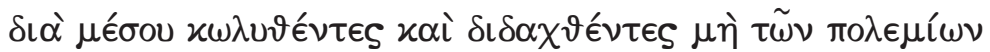

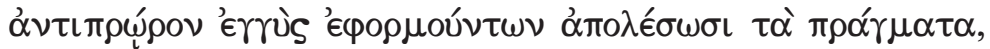

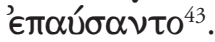

A este concepto es posible asociar también, siguiendo la lectura atenta de Tucídides, el concepto de $\mu$ é $\rho \rho \nu$ que significa la medida, aquella medida matemática o geométrica que nos permite conocer el volumen, altura y anchura de un objeto. También representa en el ámbito filosófico la medida en cuanto al límite que el ser humano puede llegar a conocer ${ }^{44}$, pero el historiador también la aplica para definir la moderación y la idea de centro político. De esta forma se distingue en el revelador pasaje donde se manifiesta en primera persona:

"Durante los primeros tiempos es cuando, viviendo yo, mejor se han gobernado los atenienses; pues se logró una mezcla equilibrada de la oligarquia y democracia, y de mala que era la situación fue esto lo que por primera vez hizo recobrar fuerzas a la ciudad" ${ }^{45}$.

El último grupo está representado por aquellos conceptos que cargan un importante significado de tipo moral y que desde luego reflejan la impronta sicológica y humana que Tucídides ${ }^{46}$ otorga a su historia y al sentido de la historia.

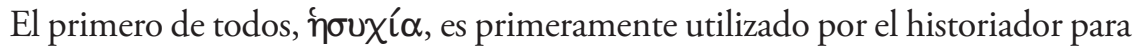
describir al ya mencionado líder ateniense Nicias ${ }^{47}$. Este vocablo indica el reposo, la paz y la tranquilidad ${ }^{48}$, no entendida como éı como garante de estabilidad en los momentos más complejos de la guerra. De esta

${ }^{43}$ Tucídides VIII, 75, 1 "Oyéndole los soldados, primero quisieron lapidar a los que habian implantado la oligarquia y a aquellos otros que habian tomado parte en la conspiración; pero después, como los moderados se lo estorbaran y aconsejaran que no lo echaran a perder al estar los enemigos anclados frente a ellos dispuestos al ataque, lo dejaron", p. 457.

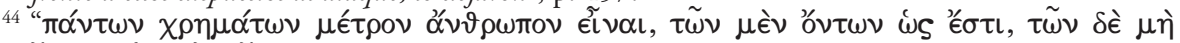

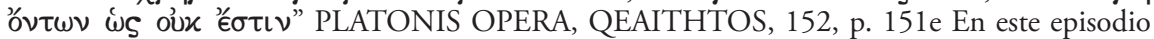
Sócrates recuerda la famosa sentencia de Protágoras: "El hombre es la medida de todas las cosas, de las que son en cuanto son y las que no son en cuanto no son".

${ }^{45}$ Tucídides VIII, 97, 2.

${ }^{46}$ Según Huart, en la historia de Tucídides es posible oponer los conceptos del vocabulario

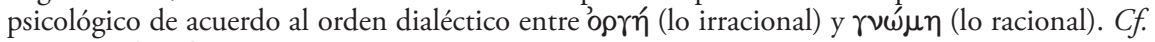
Huart, P. Op. Cit, cap. I.

${ }^{47}$ VI, 9 - 15 Discurso de Nicias a la Asamblea pidiendo mayor cautela antes de decidir si se iniciaba la campaña contra Sicilia. Alcibíades posteriormente acusa a Nicias de inactividad y falta de valor.

${ }^{48}$ Bétant, E.A, Op. Cit., pp. $457-459$ 
manera es posible asociar este concepto al personaje ya mencionado ${ }^{49}$ puesto que su gestión permite establecer una tregua (paz de Nicias, 421 - 415) que permitiese a los estados beligerantes ordenar sus propias disputas internas.

Béßoıııs indica en su forma de adjetivo la firmeza, estabilidad, certeza, constancia y seguridad que desde la perspectiva oligárquica refiere a la seguridad que ofrece un gobierno que otorga el poder a los poseedores de los mayores y mejores bienes crematísticos. En este caso particular el concepto está inmerso en un contexto opuesto y muy decidor en cuanto a significado y a la acción del $\delta \tilde{\eta} \mu \circ \varsigma_{\text {: }}$

"Por estas fechas tuvo lugar en Samos la sublevación del pueblo contra los nobles, apoyada por los atenienses, que se hallaban presentes con tres naves. El pueblo de Samos mató en total unos doscientos nobles, $y$ desterrando a cuatrocientos y distribuyéndose sus tierras y casas, como los atenienses les concedieran tras estos sucesos la autonomía para considerarlos ahora ya dignos de confianza, en adelante gobernaban ellos la ciudad y a los terratenientes"50.

Es por tanto la ausencia de estabilidad política luego del desastre de Sicilia y la muerte y desaparición de los líderes de Atenas (Nicias y Alcibíades) lo que pondrá en movimiento a los oligarcas.

La $\sigma \omega \varphi \rho \circ \sigma u ́ v \eta$ es sin duda uno de los conceptos más fuertes que implica una amplia variante de significados. La filosofía socrática incidirá posteriormente en la aprehensión de la prudencia como modo de vida y motor de acción. No obstante, será Tucídides quien en el lenguaje histórico incluirá este aspecto de tipo moral en su Historia retomando la larga tradición iniciada en período homérico para referirse a los mejores. En el caso particular del libro VIII, Huart dice que Tucídides usa este concepto para definir la forma moderada de un gobierno $^{51}$, de tal forma que la prudencia es visible como ejemplo de virtud ${ }^{52}$ la cual cobra un sentido metahistórico en la obra de historiador ateniense. No es

${ }^{49}$ Cabe señalar la referencia de Aristóteles a Nicias junto a otros líderes moderados: "Parecen haber sido los mejores de los que han gobernado en Atenas, después de los antiguos, Nicias, Tucídides [de Melesias] y Terámenes. Y sobre Nicias y Tucidides [de Melesias] todos casi están de acuerdo en que fueron hombres no sólo perfectos, sino también buenos gobernantes y que sirvieron a toda la ciudad conforme a la tradición" Aristóteles, Constitución de Atenas, 28, 5.

${ }^{50}$ Tucídides VIII, 21.

${ }^{51}$ Huart, P. Op. Cit., p. 473.

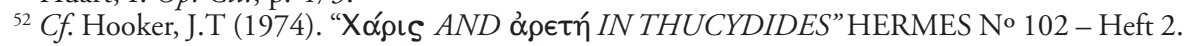


casualidad que en el mismo párrafo en que encontramos la €ưvo $\mu$ í $\alpha$ aparece la

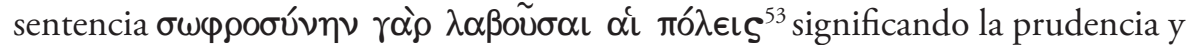
sensatez en la aprehensión de un gobierno moderado como paradigma político. Vemos de esta manera una importante cercanía entre $\sigma \omega \varphi \rho o \sigma u ́ v \eta$ y $\beta \in ́ \beta \alpha$ los que admiten la seguridad ${ }^{54}$ y la confianza de un régimen equilibrado. Este término hace referencia también a la prudencia de la antigua aristocracia que Tucídides

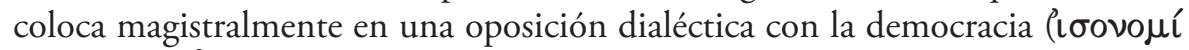

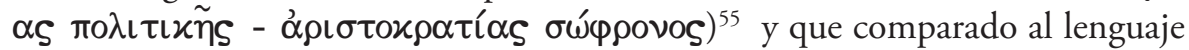
político de la oligarquía en donde Pisandro, líder del movimiento, llama a preferir

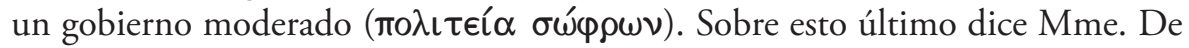
Romilly que Pisandro al referirse al paso a la oligarquía no pronuncia la palabra oligarquía. Habla de una política "más sensata", un eufemismo de los que tanto han agradado siempre a los partidos reaccionarios ${ }^{56}$.

Uno de los conceptos más inquietantes es el que refiere a la salvación como argumento para cambiar drásticamente un régimen político. El término de $\sigma \omega \tau \eta \rho i ́ \alpha$ es utilizada con frecuencia en Heródoto en relación a la salvación de la opresión persa, sin embargo Tucídides la incluye posteriormente en el contexto de la descripción de la propaganda lacedemonia como modelo de gobierno para toda Grecia $^{57}$. En ambos casos, la salvación va de la mano con la sublime idea helénica de ' $\epsilon \lambda \in \cup \vartheta \in \rho i ́ \alpha$, la libertad que conduce a los hombres a la ansiada $\epsilon \cup \delta \alpha \iota \mu o v i ́ \alpha$. Libertad y salvación se convierten entonces en un solo paradigma que un grupo político ofrece y desea perpetuar. El ejemplo más evidente se encuentra en el discurso fúnebre de Pericles ${ }^{58}$, pero en el libro VIII se hace más latente aún

53 Tucídides, VIII, 64,5, traducido por Hornblower como "para cuando las ciudades aseguraron un gobierno sensato"Vs. Hornblower, S. Op. Cit. p. 942.

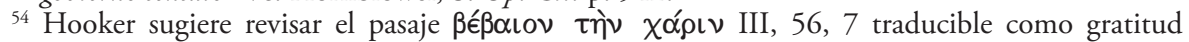
permanente y firme Cf. Hooker, J.T, Op.Cit., p. 168, a la cual podemos aplicar la estabilidad

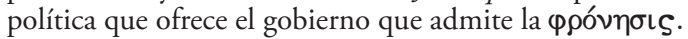

55 Tucídides III, 82, 8.

${ }^{56}$ De Romilly, J (1966) “Alcibiades o los peligros de la ambición” Ed. Seix Barral, Barcelona, p. 158.

${ }^{57}$ Tucídides II, 11 Discurso del rey Arquidamo "Porque Grecia entera está pendiente de esta empresa y nos dedica su atención, deseando por odio a los atenienses que llevemos a efecto nuestros planes" p. 78.

${ }^{58}$ Tucídides, II, 37, 2 "Y nos regimos libremente no sólo en lo relativo a los negocios públicos, sino también en lo que se refiere a las sospechas recíprocas sobre la vida diaria, no tomando mal al prójimo que obre según su gusto, ni poniendo rostros llenos de reproche, que no son un castigo, pero si penosos de ver" p. 90; para el concepto de Libertad Democrática Vs. De Romilly, J. (1989) "La Grèce antique à la découverte de la liberté" Éditions de Fallois, Paris, donde la historiadora hace hincapié en la existencia de libertades individuales no aplicable a reivindicaciones en plural, donde cada ciudadano hacía uso personal o grupal de sus derechos, el caso más paradigmático es el de la parresía (derecho a hablar libremente en la Asamblea) cap. III. 
tomando en consideración que luego del desastre de Sicilia esta palabra estaba en boca de todos y los antidemocráticos aprovecharon este derrotismo ${ }^{59}$, lo que significaba que la salvación de Atenas era para los antidemocráticos el abandono de la constitución democrática y por ende del imperio ${ }^{60}$.

Пó́ $\chi \chi \omega$ en tanto sufrimiento y padecimiento, que en la lengua griega de los Evangelistas adquirió una connotación fundacional del credo cristiano, posee en Tucídides una ligazón literaria que permite caracterizar estados de ánimo de una sociedad en un contexto de extrema conmoción bélica. No son nuevos los estudios acerca de las conexiones literarias entre los trágicos griegos y el historiador Tucídides ${ }^{61}$ y la evidencia en su propia obra demuestra cómo hace partícipe la idea de sufrimiento ${ }^{62}$ del hombre en pos de no claudicar a la propia libertad. Reconocemos en la peste de Atenas (Libro II, 47 - 54), la guerra civil de Córcira (Libro III, $82-84$ ), la crueldad de Cleón y el castigo a los sublevados de Mitilene (Libro III, 37 - 40), la matanza en el río Asínaro y la derrota absoluta de los atenienses en Sicilia (Libro VII, 79 - 87) y finalmente en la descripción del golpe oligárquico del 411 a.C. (Libro VIII, 66) la presencia de un historiador que desea imprimir un carácter psicológico a una humanidad que según él no cambia $^{63}$. Lo anterior ha sido motivo de críticas al historiador al cual le ha sido otorgada la etiqueta de pesimista.

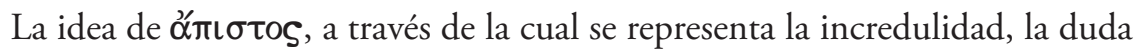
y desconfianza, está inmersa en la descripción del golpe oligárquico con aquella carga psicológica que imprime Tucídides a su relato. En este sentido, siguiendo la atenta lectura de la obra de Huart, el analista francés en su capítulo dedicado a las emociones ${ }^{64}$ nos dice que de diversas formas el historiador ateniense pretende revelar estados de ánimo a través de la narración histórica. Junto con $\alpha \pi \imath \sigma \tau i ́$

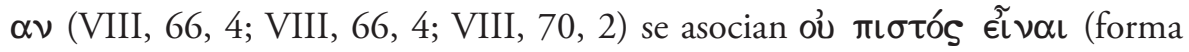
condicional negativa VIII, 51,3), y luego ̇̀толтоৎ entendida como la sospecha y desconfianza (VIII, 63, 2; VIII, 66, 5; VIII, 68, 1). De esta manera el historiador

${ }^{59}$ Cecchin, S.A. (1969), Op.Cit, p. 2.

${ }^{60}$ Ídem, pp. $2-3$

${ }^{61}$ Vs. Finley, J.H (1938) "Euripides and Thucydides" Harvard Studies in Classical Philology, Vol. 49; Finley, J.H (1939), "The Origin of Thucydides' Style” Harvard Studies in Classical Philology, Vol. 50.

${ }^{62}$ Es interesante notar además el uso de otros conceptos asociados al sufrimiento como róvos y $\pi 0 \nu \tilde{\imath} \nu$ que significa la pena y el dolor y $\varkappa \alpha \tau \alpha \pi \lambda \eta^{\prime} \xi$ เৎ, utilizada por el historiador para describir la sensación de abatimiento luego del desastre en Sicilia. Abatimiento que da paso al estupor y a la desesperación. Vs. Huart, P. Op. Cit, p. 114 y ss.

${ }^{63}$ Tucídides I, 22,4.

${ }^{64}$ Huart, P. Op. Cit. Cap. II Les Emotions, pp. 80 - 89. 
crea un clima particular de intriga en un contexto donde "el pueblo ateniense no llegó nunca a descubrir los nombres y características de los conjurados' ${ }^{265}$.

El último concepto, y quizás uno de los más paradigmáticos en cuanto a historia psicológica, es el de póßos (miedo). Sabemos que a través de toda la historia que Tucídides presenta, el miedo configura uno de los elementos que mueve a la acción - y sin duda a la humanidad entera todavía ${ }^{66}$ - utilizándolo como causa primera y más verdadera ( $\left.\alpha \lambda \eta \vartheta \in \sigma \tau \alpha^{\prime} \tau \eta ~ \pi \rho o ́ \varphi \alpha \sigma ı \varsigma\right)$ del origen de la guerra ${ }^{67}$ y del imperio ateniense $^{68}$. Sin embargo en el libro VIII el miedo cobra un sentido intrínsicamente social al abordar el temor y la angustia que se genera en Atenas al momento de la toma del poder por parte de los oligarcas. Фóßos junto a $\varphi \circ \beta \tilde{\epsilon} \sigma \vartheta \alpha \iota$ indican en este episodio ${ }^{69}$ el miedo al retorno de la tiranía ${ }^{70}$, puesto que ésta se encontraba permanentemente en los discursos de los líderes democráticos con el fin de consolidar el gobierno del $\delta \tilde{\eta} \mu \varsigma^{71}$. Un miedo que efectivamente se hace patente con el asesinato de personajes ligados a la democracia, pero particularmente por el curso que podía tomar una guerra ya desgastada.

De esta manera es posible acercarse al lenguaje del historiador ateniense que busca

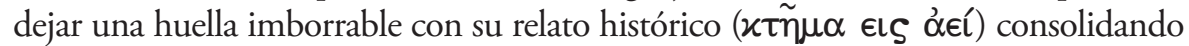
de esta manera un estilo propio que constituirá un modelo para los historiadores posteriores. El libro VIII, inconcluso, deja muchas interrogantes acerca de los hechos sucesivos y de la opinión que pudo haber tenido el autor sobre la reinstauración de la democracia y la condena a los oligarcas de la conjura. Este acotado análisis busca entonces generar la instancia de discusión sobre estos acontecimientos.

${ }^{65}$ Tucídides VIII, 66, 3.

${ }^{66}$ Vs. Delumeau. J, (2012) "El Miedo en Occidente” Taurus, Madrid.

${ }^{67}$ Tucídides I, 23, 6: "Creo, a saber, de acuerdo con la causa más verdadera, pero menos aparente por lo que se dice, que los atenienses, al hacerse poderosos y producir miedo a los lacedemonios, les forzaron a luchar"p. 14.

${ }^{68}$ Tucídides I, 76, 2 "Por tanto, no hemos hecho nada digno de extrañeza ni fuera de la naturaleza humana al aceptar un imperio que se nos daba y no abandonarlo cediendo a los tres motivos más fuertes: la honra, el miedo y el interés" p. 38.

${ }^{69}$ Tucídides VIII, 73, $3-6$.

${ }^{70}$ Sobre este punto, D. Plácido dice que "En verdad, en Atenas era difícil la vuelta de los tiranos casi cien años después de su expulsión, habida cuenta de que el demos no sólo no estaba sometido, sino que estaba acostumbrado a mandar (VIII, 68, 4)" Plácido, D. Op. Cit. p. 163.

${ }^{71}$ Una sugerente hipótesis sostiene M. Taylor al señalar que el pueblo ateniense tuvo responsabilidades en el golpe de estado oligárquico y que la mayoría de los historiadores insinúan que Tucídides se esmera en relatar el clima de terror y propaganda cuando, por el contrario, el historiador ateniense busca acusar también al pueblo. Cfr. Taylor, M.C.(2002) "Implicating the demos: a reading of Thucydides on the rise of the Four Hundred"JHS Vol. 122. 


\section{Referencias bibliográficas}

\section{Fuentes}

Platonis Opera (1967) Tomvs I, Scriptorvm Classicorvm Bibliotheca Oxoniensis, Oxonii e Typographeo Clarendoniano, Great Britain.

Tucidide, (2011 12) "La Guerra del Peloponneso" BUR Rizzoli, Classici Greci e Latini, Milano.

Thucydide (2003) "La Guerre du Péloponnèse” Les Belles Lettres, Paris.

Tucídides, (2002) "Historia de la Guerra del Peloponeso", Centro de Estudios Políticos y Constitucionales, Madrid.

Xénophon (1960) “Helléniques”Les Belles Lettres, Paris.

\section{Bibliografía consultada}

Bétant, E. A. $\left(1961^{2}\right)$, “Lexicon Thucydideum”, G. Olms, Hildesheim.

Canfora, L. (1980) "Oratoria Politica e Giudiziaria in Atene" en Atti del Convegno sulla Lessicografia Politica e Giuridica nel campo delle scienze dell'Antichità (Torino, 28-29 aprile 1978), Torino.

Canfora, L. (2001), “El misterio Tucídides” Aldebarán Ediciones, Madrid.

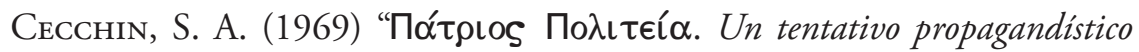
durante la guerra del Peloponneso" Historia Politica Philosophica 1, Paravia, Torino.

De Romilly, J. (1989) “La Grèce antique à la découverte de la liberté" Éditions de Fallois, Paris.

Gomme, A. W., Andrewes, A., Dover, K.J. (1981), “A Historical Commentary on Thucydides" Oxford Clarendon Press.

Graham, A. J. - Forsythe, G. (1984), "A New Slogan for Oligarchy in Thucydides III.82.8” en Harvard Studies in Classical Philology, Harvard University Press.

Hornblower, S. (2008) “A Commentary on Thucydides" Vol III, Oxford University Press.

Huart, P. (1968) "Le vocabulaire de l'analyse psychologique dans l'oeuvre de Thucydide" Librairie C. Klincksieck, Paris.

SARTORI, F. (1957) "Le eterie nella vita politica ateniese del VI e V secolo a.C." L'Erma di Bretschneider, Roma. 
Whibley, L. (1896) "Greek Oligarchies. Their character and organisation" Methuen \& Co, Cambridge.

\section{Revistas y publicaciones periódicas}

Canfora, L (1992) "Hobbes e Tucidide" QS, No35.

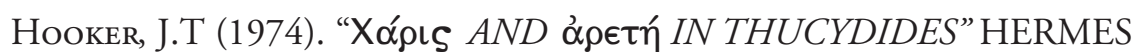
No 102 - Heft 2.

López EIre, A. (1990) "La revolución en el pensamiento politico de Tucídides (I)" Gerión No 8, Universidad Complutense de Madrid

Ostwald, M. (2000), "Oligarchia. The Development of a Constitutional form $a$ ancient Greece" HISTORIA, Heft 144.

Plácido, D. (1989) “Tucídides, sobre la tiranía” en Gerión, Anejos II, Estudios sobre la antigüedad en homenaje al profesor Santiago Montero Díaz, Universidad Complutense de Madrid.

Pope, M. (1988), "Thucydides and Democracy”, HISTORIA, Band XXXVII.

Silvestrini, M. (1976) "Diplomazia e complotti oligarchici a Chio e Rodi (Tucidide, VIII, 5-44)”QS, No 3.

TAYLOR, M. C. (2002) "Implicating the demos: a reading of Thucydides on the rise of the Four Hundred"JHS Vol. 122. 